$16^{\circ}$ USIHC - Congresso Internacional de Ergonomia e Usabilidade de CINAHPA

\title{
CONDIÇÃO REAL DE TRABALHO DO SERVENTE DE OBRA NA PRODUÇÃO DE ARGAMASSAS EM CRICIÚMA
}

\section{ACTUAL WORKING CONDITION OF A HOD CARRIER IN THE MORTARS PRODUCTION IN CRICIÚMA}

Heloisa Nunes e Silva ${ }^{1}$, M.Sc.

(1) Instituto Federal de Santa Catarina

e-mail: heloisa.nunes@ifsc.edu.br

Ergonomia, Servente de obra, Segurança do trabalho.

Analisa a condição real de trabalho do servente de obra no processo de produção de argamassas no canteiro de obras de uma empresa construtora de Criciúma-SC, por meio da Análise Ergonômica do Trabalho realizada num estudo de caso e apontando os conflitos e as soluções para a tarefa.

\section{Ergonomics, Hod carrier, Work Safety.}

This study deals with the actual work condition of the a hod carrier in the process of production of mortars at the construction site of a construction company in Criciuma-SC, using the method of Ergonomic Analysis of Work (AET), through the Ergonomic Analysis of Work carried out in a case study and pointing out the conflicts and solutions for the assignment. 


\section{$16^{\circ}$ \\ ERGODESIGN USIHC CINAHPA}

$16^{\circ}$ Ergodesign - Congresso Internacional de Ergonomia e Usabilidade de Interfaces Humano Tecnológica: Produto, Informações Ambientes Construídos e Transporte

$16^{\circ}$ USIHC - Congresso Internacional de Ergonomia e Usabilidade de Interfaces Humano Computador

CINAHPA | 2017 - Congresso Internacional de Ambientes Hipermídia para Aprendizagem.

\section{Introdução}

O ciclo do processo da construção de edifícios é complexo e envolve etapas de definição das empresas construtoras da obra; do terreno; do projeto da edificação e da execução, que finaliza com a entrega da edificação ao cliente. Neste ciclo, a etapa de execução da edificação engloba também a materialização do canteiro de obras, que se caracteriza como um ambiente de trabalho sazonal e que engloba diversas atividades além da produção, entre elas a de moradia, de lazer, de convívio social, de aprendizado, de circulação.

Observa-se que o canteiro de obra costuma ser desfavorecido de investimentos materiais e financeiros, pelo seu fator de transitoriedade. Os reflexos dessa prática afetam negativamente às condições de habitabilidade e na adequação das áreas de trabalho do canteiro de obras. As pesquisas de Saurin\& Formoso (2006) apontam que o planejamento do espaço do canteiro de obras tem sido negligenciado no gerenciamento da construção, sendo as decisões tomadas à medida que os problemas surgem, no decorrer da execução. Essa inadequação espacial poderá resultar em condições insalubres de trabalho, representando danos à saúde da equipe e, numa escala maior, à sociedade.

A construção de Civil é um Setor que representa grande importância no universo produtivo da economia brasileira. Os dados do Instituto Brasileiro de Geografia e Estatística (IBGE) relativos ao ano de 2013 - data base agosto demonstram que o setor responde por $5,7 \%$ do Produto Interno Bruto (PIB) nacional e propicia 146 mil empregos formais nesse mercado de trabalho. Esse grande contingente de trabalhadores está diariamente dentro do canteiro de obra executando uma rotina exaustiva de serviços, condicionado a usufruir a área do canteiro de obra, mesmo que inadequada.

A realidade desse espaço emerge conflitos da ordem de ambiente construído (ex:.ventilação, luz, área de ambiente), de organização espacial do canteiro de obras, de descumprimento de requisitos legais de segurança do trabalho e de situações ergonômicas conflituosas no processo do trabalho em obra.

A Análise Ergonômica do Trabalho (AET) mostra que o homem leva em conta muitas coisas durante a execução de uma tarefa aparentemente simples (Wisner, 1994).

A metodologia de AET consiste em investigar uma demanda definida pelo cliente e é realizada por meio de técnicas que buscam conhecer a tarefa prescrita, reconhecer a atividade executada, diagnosticar os fatores intervenientes no processo, indicar soluções para atender à demanda inicial, avaliar a efetividade das soluções e a indicação de ajustes às propostas.

A AET está amparada legalmente pela Norma Regulamentadora 17 - Ergonomia, da Portaria $\mathrm{n}^{\mathrm{o}}$ 3.214/78 - Segurança e Medicina do Trabalho, do Ministério do Trabalho e Emprego do Brasil.

O objetivo deste artigo é abordar a condição real de trabalho do servente de obra na elaboração de argamassas de cimento dentro de um canteiro de obras na cidade de Criciúma/SC e seus reflexos na organização, no trabalhador e na saúde e segurança do trabalho.

\section{Fundamentação}

\subsection{Canteiro de Obras}

Na norma ABNT NBR 12.284 (1991) e Norma Regulamentadora 18 - Condições e Meio Ambiente de Trabalho na Indústria na Construção, Da Portaria $n^{\circ}$ 3.214/78 - Segurança e Medicina do Trabalho, do Ministério do Trabalho e Emprego do Brasil, definem canteiro de obras como áreas destinadas à execução e apoio dos trabalhos da indústria da construção, dividindo-se em áreas operacionais e áreas de vivência. A elaboração do projeto do canteiro de obra deve estar sob responsabilidade da equipe de engenharia e arquitetura das empresas, devendo ser aprovado pelo corpo técnico da empresa antes da sua implantação no terreno, a fim de evitar rearranjos físicos futuros e situações técnicas problemáticas. 


\section{$16^{\circ}$ \\ ERGODESIGN USIHC CINAHPA}

$16^{\circ}$ Ergodesign - Congresso Internacional de Ergonomia e Usabilidade de Interfaces Humano Tecnológica: Produto, Informações Ambientes Construídos e Transporte

$16^{\circ}$ USIHC - Congresso Internacional de Ergonomia e Usabilidade de Interfaces Humano Computador

CINAHPA | 2017 - Congresso Internacional de Ambientes Hipermídia para Aprendizagem.
Ferreira (1998) apresenta alguns princípios gerais que o projeto do canteiro de obras pode evidenciar, tais como reduzir, minimizar ou eliminar as perdas, assim como as considerações sobre a determinação da localização dos elementos no canteiro, como acessos, almoxarifado, escritório, banheiro, refeitório, etc. O terreno também influenciará nas instalações a ser construídas. $\mathrm{O}$ autor sinaliza que o arranjo físico do canteiro deve ser elaborado com o objetivo de aperfeiçoar o seu funcionamento global, considerando a capacidade efetiva da obra, a segurança das instalações e a produtividade das operações. Após a definição do arranjo físico das diversas fases do canteiro, deve-se realizar o detalhamento dos elementos, com a divisão funcional dos ambientes e a localização de móveis, máquinas e equipamentos, de modo a otimizar os fluxos dos processos, reduzir perdas, evitar interferências e aproximar as atividades que têm maior grau de inter-relações.

\subsection{Ergonomia}

Para a Associação Internacional de Ergonomia (IEA), entende-se Ergonomia como sendo "a disciplina científica que diz respeito ao entendimento das interações entre homens e os outros elementos de um sistema, a profissão que aplica teorias, princípios, dados e métodos para projetar de modo a otimizar o bem-estar dos homens e a eficiência total do sistema". Ela é composta por três abordagens: a ergonomia física (relacionada à anatomia humana), a ergonomia cognitiva (relacionada aos processos mentais) e a ergonomia organizacional (relacionada aos sistemas sociotécnicos da organização).

A abordagem ergonômica considera uma situação problemática real de uma tarefa determinada, de modo a reconhecer as atividades executadas pelos seus operadores, permitindo indicar a influência de cada parcela da ergonomia (física, cognitiva, organizacional) sobre o trabalho em análise.

Wisner (1994) orienta que para saber como alguém pensa, também é preciso se interessar por ele, dar voz a suas demandas. $\mathrm{O}$ autor comenta que a AET interessa-se por toda a atividade do trabalho, incluindo as atividades que não dizem respeito à tarefa prescrita como as atividades cognitivas e fenômenos psíquicos habituais. Ainda, ele aborda que toda atividade física (envolve uma carga física) tem atividade cognitiva (relacionada a uma carga mental), quando esta é desprezada numa análise originam-se os problemas. Há ampla literatura para carga física, porém pouco ligada à realidade e à complexidade das situações de trabalho. Ademais, Wisner adota a terminologia de Carga de Trabalho (mais tarde nominada de Fadiga) como o termo utilizado para descrever os efeitos negativos do trabalho sobre os próprios trabalhadores e seus colegas. Assim, o autor argumenta que não se deve mais protelar o estudo do trabalho dos operadores e os efeitos que esse trabalho tem sobre seu psiquismo. E a AET é a ferramenta adequada para apurar essa situação.

\subsection{Servente de Obras}

A função de Servente de Obras é regulamentada pelo Cadastro Brasileiro de Ocupações (CBO) como código 7170-20, em que estabelece objetivos pertinentes a ela: "Demolem edificações de concreto, de alvenaria e outras estruturas; preparam canteiros de obras, limpando a área e compactando solos. Efetuam manutenção de primeiro nível, limpando máquinas e ferramentas, verificando condições dos equipamentos e reparando eventuais defeitos mecânicos nos mesmos. Realizam escavações e preparam massa de concreto e outros materiais".

A tarefa do servente de obras na empresa analisada compreende limpeza de área, elaboração de argamassas, reposição de insumos no canteiro de obras e auxílio nas atividades dos pedreiros de alvenaria. A jornada de trabalho é de 08(oito) horas diárias, sendo das $7 \mathrm{~h}$ às $12 \mathrm{~h}$ e das $13 \mathrm{~h}$ às $17 \mathrm{~h}$. Trabalham 5 dias na semana. $O$ intervalo do almoço é de $1 \mathrm{~h}$ e há pausa para o café da manhã das $8: 30 \mathrm{~h}$ às $8: 40 \mathrm{~h}$, sendo dentro da jornada de trabalho. A operação de produção de argamassa sempre é realizada em dupla pelos serventes de obras.

A hierarquia nas relações de trabalho estabelece que o servente de obras esteja submetido às ordens do pedreiro/carpinteiro / armador e também do
Realização:
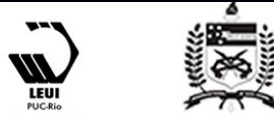


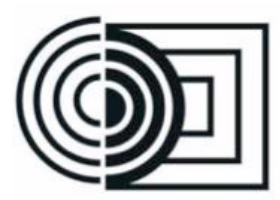

mestre de obras, sendo que o engenheiro civil é o responsável pelo gerenciamento total da obra.

As ferramentas disponíveis no posto de trabalho são: carrinho de mão, arames e ferragens, torquês e alicate universal, balde e lata de 20 litros, betoneira de concreto (400L), espátula e escova de aço, enxada, enxadão, pá, rastelo, picareta, marreta, martelo, serrote e chaves de fixação, talhadeira e ponteiro, madeiras, tijolos cerâmicos e de cimento, saco de cimento, areia, cal e brita, galão de aditivos, padiola de madeira para dosagem de insumos, caneco/concha da grua (recipiente para carregar argamassas).

\section{Método}

A metodologia da AET utiliza-se de diferentes técnicas buscando compreender as atividades nas suas diferentes dimensões (física, cognitiva e social). Inicia-se pela definição da demanda, seguindo pelo estudo do funcionamento da organização, dos processos de produção e das atividades do trabalho. O reconhecimento da atividade do trabalho real executado pelo operador dará embasamentos técnicos para a formulação do diagnóstico e as recomendações propostas. No quadro abaixo se apresenta a estrutura de coleta de dados aplicada nesta AET:

\begin{tabular}{|l|l|l|}
\hline Método & Técnica & Finalidade \\
\hline $\begin{array}{l}\text { Análise } \\
\text { Documental }\end{array}$ & $\begin{array}{l}\text { Registros da } \\
\text { empresa, literatura } \\
\text { específica, } \\
\text { legislações. }\end{array}$ & $\begin{array}{l}\text { Conhecer e identificar } \\
\text { conteúdos norteadores } \\
\text { para a AET }\end{array}$ \\
\hline Observação & $\begin{array}{l}\text { Filmagem } \\
\text { Registroescrito }\end{array}$ & $\begin{array}{l}\text { Reconhecer os } \\
\text { movimentos corporais, } \\
\text { as ações tomadas pelo } \\
\text { operador, verificar as } \\
\text { dificuldades }\end{array}$ \\
\hline Entrevista & $\begin{array}{l}\text { Questionário aberto } \\
\text { semi estruturado } \\
\text { Análise do discurso }\end{array}$ & $\begin{array}{l}\text { Coletar as percepções } \\
\text { do operador sobre sua } \\
\text { atividade }\end{array}$ \\
\hline $\begin{array}{l}\text { AvaliaçãoQ } \\
\text { uantitativa }\end{array}$ & $\begin{array}{l}\text { Medição no } \\
\text { ambiente construído, } \\
\text { do maquinário e do } \\
\text { operador }\end{array}$ & $\begin{array}{l}\text { Relacionar as medidas } \\
\text { entre o operador e os } \\
\text { dispositivos no local de } \\
\text { trabalho } \\
\text { - Coletar dados do nível } \\
\text { de esforço físico do } \\
\text { operador }\end{array}$ \\
\hline
\end{tabular}

Quadro 1- Estrutura de pesquisa. Fonte: Os autores. $16^{\circ}$ Ergodesign - Congresso Internacional de Ergonomia e Usabilidade de Interfaces Humano Tecnológica: Produto, Informações Ambientes Construídos e Transporte

$16^{\circ}$ USIHC - Congresso Internacional de Ergonomia e Usabilidade de Interfaces Humano Computador

CINAHPA | 2017 - Congresso Internacional de Ambientes Hipermídia para Aprendizagem.

\subsection{Local de Estudo de Caso}

A cidade de Criciúma situa-se no extremo sul catarinense, a $200 \mathrm{~km}$ de Florianópolis, e destaca-se na economia nacional pelo setor cerâmico e em nível estadual pelos setores metalúrgicos, supermercadista, vestuário, carvão, construção de edifícios e setor químico. A população é de 202.395 habitantes, segundo estimativa do IBGE em 2013.

Realizou-se um estudo de caso em uma empresa construtora de edifícios residenciais na cidade e se analisou a produção de argamassas em obra, considerando a função do servente de obras, tendo como critério de seleção do local/construtora estar em estágios de execução da obra com produção de argamassas de cimento e ter autorização da empresa para acesso a documentos com possibilidade de registro fotográfico da obra.

A demanda da AET é originada pela gerência da empresa que solicita a otimização do processo de produção de argamassas em obra. A construtora é de pequeno porte e com 10 anos de experiência no ramo da construção civil.

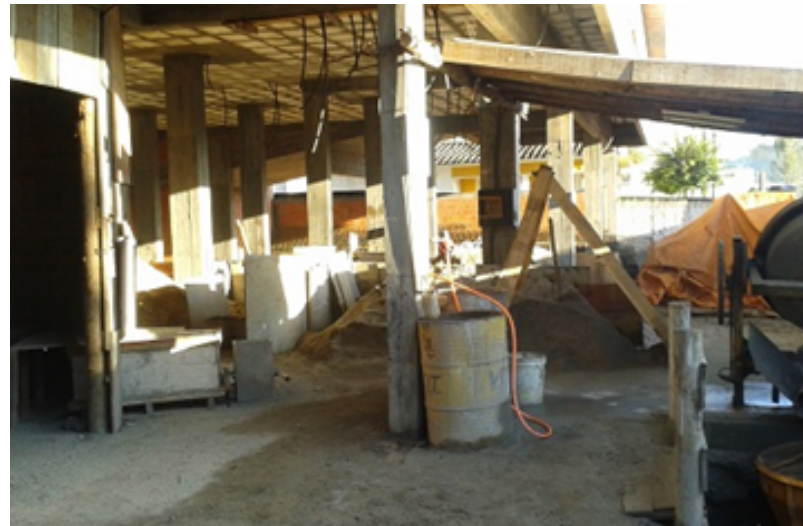

Figura 1- Imagem geral do posto de trabalho de produção de argamassas. Fonte: Os autores

\subsection{Norma Regulamentadora 17 - Ergonomia}

No âmbito legal, a AET baseia-se nas diretrizes da Norma Regulamentadora $\mathrm{n}^{\mathrm{o}} 17$ aprovada pela Portaria $\mathrm{n}^{\mathrm{0}} 3.751$, de 23/11/90, sendo observados os seguintes itens/aspectos destacados no quadro 2 :
Realização:

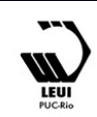




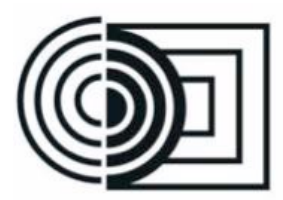

$16^{\circ}$ Ergodesign - Congresso Internacional de Ergonomia e Usabilidade de Interfaces Humano Tecnológica: Produto, Informações Ambientes Construídos e Transporte

$16^{\circ}$ USIHC - Congresso Internacional de Ergonomia e Usabilidade de Interfaces Humano Computador

CINAHPA | 2017 - Congresso Internacional de Ambientes Hipermídia para Aprendizagem.

\begin{tabular}{|c|c|}
\hline Item & Descrição da orientação emitida na NR-17 \\
\hline \multirow[t]{2}{*}{17.2} & $\begin{array}{l}\text { Levantamento, transporte e descarga individual } \\
\text { de materiais }\end{array}$ \\
\hline & $\begin{array}{l}\text { Deverão ser executados de forma que o esforço } \\
\text { físico realizado pelo trabalhador seja compatível } \\
\text { com sua capacidade de força e não comprometa a } \\
\text { sua saúde ou sua segurança. }\end{array}$ \\
\hline \multirow[t]{4}{*}{17.3} & Mobiliário dos postos de trabalho \\
\hline & $\begin{array}{l}\text { Para as atividades em que os trabalhos devam ser } \\
\text { realizados de pé, devem ser colocados assentos } \\
\text { para descanso em locais em que possam ser } \\
\text { utilizados por todos os trabalhadores durante as } \\
\text { pausas. }\end{array}$ \\
\hline & Os comandos sejam de fácil acionamento \\
\hline & Osassentossejamadequados \\
\hline \multirow[t]{2}{*}{17.4} & Equipamentos dos postos de trabalho \\
\hline & $\begin{array}{l}\text { Todos os equipamentos que compõem um posto } \\
\text { de trabalho devem estar adequados às } \\
\text { características psicofisiológicas dos trabalhadores } \\
\text { e à natureza do trabalho a ser executado }\end{array}$ \\
\hline \multirow[t]{3}{*}{17.5} & Condiçõesambientais de trabalho \\
\hline & $\begin{array}{l}\text { As condições ambientais de trabalho devem estar } \\
\text { adequadas às características psicofisiológicas dos } \\
\text { trabalhadores e à natureza do trabalho a ser } \\
\text { executado }\end{array}$ \\
\hline & $\begin{array}{l}\text { Em todos os locais de trabalho deve haver } \\
\text { iluminação adequada, natural ou artificial, geral } \\
\text { ou suplementar, apropriada à natureza da } \\
\text { atividade }\end{array}$ \\
\hline \multirow[t]{3}{*}{17.6} & Organização do Trabalho \\
\hline & $\begin{array}{l}\text { as normas de produção; o modo operatório; a } \\
\text { exigência de tempo; } \\
\text { a determinação do conteúdo de tempo; o ritmo de } \\
\text { trabalho; } \\
\text { o conteúdo das tarefas; }\end{array}$ \\
\hline & $\begin{array}{l}\text { Nas atividades que exijam sobrecarga muscular } \\
\text { estática ou dinâmica do pescoço, ombros, dorso e } \\
\text { membros superiores e inferiores, e a partir da } \\
\text { análise ergonômica do trabalho, deve ser } \\
\text { observado o seguinte: } \\
\text { a) todo e qualquer sistema de avaliação de } \\
\text { desempenho para efeito de remuneração e } \\
\text { vantagens de qualquer espécie deve levar em } \\
\text { consideração as repercussões sobre a saúde dos } \\
\text { trabalhadores; } \\
\text { b) devem ser incluídas pausas para descanso; } \\
\text { c) quando do retorno do trabalho, após qualquer } \\
\text { tipo de afastamento igual ou superior a } 15 \\
\text { (quinze) dias, a exigência de produção deverá } \\
\text { permitir um retorno gradativo aos níveis de } \\
\text { produção vigentes na época anterior ao } \\
\text { afastamento. }\end{array}$ \\
\hline
\end{tabular}

Quadro2 - Diretrizes da NR-17 para considerações nesta AET. Fonte: Os autores

\subsection{Análise da Tarefa}

A tarefa corresponde ao conjunto de objetivos designados ao trabalhador e a um conjunto de prescrições definidas externamente ao trabalho para atingir esses objetivos (Gontijo, 2016).

Para a preparação de argamassas, o mestre de obras ou o pedreiro solicita ao servente de obras o tipo de argamassa que necessita e a quantidade. $\mathrm{O}$ traço da argamassa é relacionado com o tipo que será produzido: argamassa de assentamento ou argamassa para concreto. Cada qual possui um quadro fixado na parede da área de produção de argamassas em que constam informações acerca do quantitativo de insumos necessários. Ver figuras 1 e 2. Ao longo da jornada de trabalho, os serventes de obras realizam várias vezes a mesma operação de produção de argamassa, havendo tempo para reposição de insumos, limpeza do posto de trabalho e auxílio ao pedreiro de alvenaria.

Os equipamentos de proteção individual fornecidos são: luva de látex e de couro de raspa, máscara semi-facial, capacete, botina de segurança, protetor auricular, óculos de proteção. Ver figura 2.

O ambiente construído que abriga o posto de trabalho é provisório, apresenta cobertura em telhas de fibrocimento, aberto nas laterais, com piso cimentado, iluminação artificial ( 01 lâmpada) e natural.

A ventilação é natural e ampla, pois não há paredes. Ver figura 1 . O posto de trabalho fica muito próximo da rua, que tem movimento intenso.

Os indicadores de riscos ambientais monitorados pela empresa, relatam sobre os riscos físicos para o posto de trabalho com a betoneira em movimento num dia normal a dose de ruído de $98 \mathrm{~dB}(\mathrm{~A})$, considerando o ruído de fundo oriundo da via movimentada; e não há medições sobre vibrações, calor e frio. Sobre os riscos químicos, o servente de obras tem contato com cimento ( produto álcalis) na forma sólida, de poeiras e após a mistura com água tornando-se argamassa de forma pastosa. Outro produto é o aditivo químico (cloreto) para acelerar a resistência do concreto e é manipulado na forma líquida. A areia manipulada é na forma sólida e de poeiras em suspensão. Não há medição de nível de luminosidade no local.

A operação do posto de trabalho está exposta à intempérie (vento, chuva, frio, calor) e há trabalho a céu aberto em alguns períodos, como no caso da manipulação do caneco/concha da grua. 


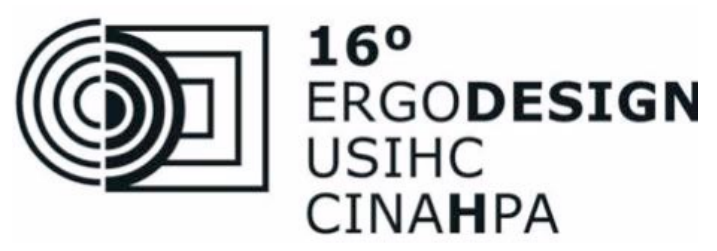

$16^{\circ}$ Ergodesign - Congresso Internacional de Ergonomia e Usabilidade de Interfaces Humano Tecnológica: Produto, Informações Ambientes Construídos e Transporte

$16^{\circ}$ USIHC - Congresso Internacional de Ergonomia e Usabilidade de Interfaces Humano Computador

CINAHPA | 2017 - Congresso Internacional de Ambientes Hipermídia para Aprendizagem.
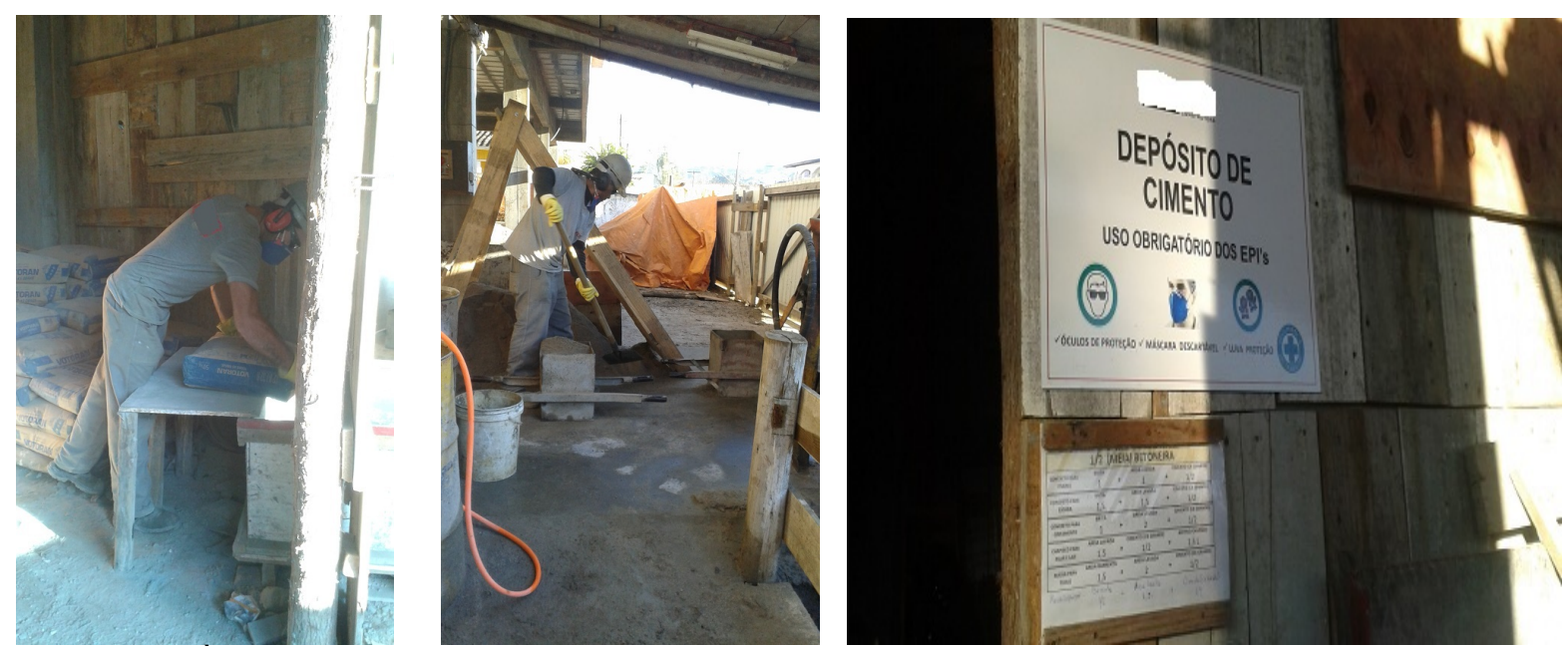

Figura 2 - À esquerda, reposição de insumos; ao centro, padiola de dosagem de insumos, e à direita, quadro com informações sobre quantidades de insumos para cada argamassa. Fonte: Os autores.

\subsection{Análise da Atividade}

A atividade de trabalho é como o operador se organizou para atingir a meta da tarefa prescrita, envolvendo sua compreensão da atividade de forma personalizada e o uso de estratégias pessoais.

$\mathrm{Na}$ análise da atividade de trabalho realizaram-se observações e entrevistas com cada operador do posto de trabalho de produção de argamassa, além de entrevista com mestre de obra, engenheiro civil e técnico em segurança no trabalho da empresa.

A descrição da atividade executada compreende o trabalho em dupla, podendo haver rodízio entre eles sobre quais objetivos da tarefa realizam. Essa definição é tomada entre eles por meio de conversa direta. As verificações realizadas na execução da atividade são apresentadas nos quadros 3 e 4 :

\begin{tabular}{|c|c|c|c|}
\hline Tempo & \multicolumn{2}{|c|}{ Descrição das atividades } & \multirow{2}{*}{$\begin{array}{l}\text { Tempo } \\
\text { minutos }\end{array}$} \\
\hline minutos & Trabalhador W & Trabalhador V & \\
\hline \multirow[b]{3}{*}{1} & liga betoneira & encher padiola de areia barrenta & \\
\hline & colocar água no balde & encher padiola de cimento & \\
\hline & colocar água na betoneira & encher padiola de areia peneirada & 1 \\
\hline & \multicolumn{2}{|c|}{ colocar padiola de areia peneirada } & \\
\hline 0,5 & \multicolumn{2}{|c|}{ colocar padiola de cimento } & 0,5 \\
\hline 1 & \multicolumn{2}{|c|}{ aguardar um pouco } & 1 \\
\hline 0,5 & \multicolumn{2}{|c|}{ colocar padiola de areia barrenta } & 0,5 \\
\hline 5 & \multicolumn{2}{|c|}{ Aguardar 5 minutos } & 5 \\
\hline \multirow[b]{3}{*}{1,5} & girar o tambor da betoneira & $\begin{array}{c}\text { ajustar o carrinho/ conha ou caneco } \\
\text { da grua }\end{array}$ & \\
\hline & aguardar & $\begin{array}{c}\text { recolher com pá toda a argamassa } \\
\text { para dentro do recipiente }\end{array}$ & 1 \\
\hline & desvirar o tambor da betoneira & $\begin{array}{l}\text { engatar o gancho do cabo da grua } \\
\text { no caneco }\end{array}$ & 0,5 \\
\hline 0,5 & pegar balde de água & $\begin{array}{l}\text { Subir até o local descarregamento } \\
\text { da grua no pavimento }\end{array}$ & 1 \\
\hline 2 & limpar betoneira & Recolher a massa na carrinho & 3 \\
\hline variável & peneirar areia & $\begin{array}{c}\text { Levar até o local de solicitação da } \\
\text { argamassa }\end{array}$ & 1 \\
\hline variável & encher caixa de cimento & \begin{tabular}{|c|}
$\begin{array}{c}\text { auxiliar o pedreiro, quando neces- } \\
\text { sáno }\end{array}$ \\
\end{tabular} & variável \\
\hline $\begin{array}{c}12 \\
\text { minutos }\end{array}$ & \multicolumn{2}{|c|}{ total total } & $\begin{array}{c}14,5 \\
\text { minutos }\end{array}$ \\
\hline & média de tempo para prod & uzir 1 betoneira $=15$ minutos & \\
\hline
\end{tabular}

Quadro 3- Relação do tempo x atividade executada por servente na produção de 1 betoneira de argamassa.

Fonte: Os autores 


\section{(ㅁ) Interfaces Humano Tecnológica: Produto, Informações Ambientes Construídos e Transporte

$16^{\circ}$ USIHC - Congresso Internacional de Ergonomia e Usabilidade de Interfaces Humano Computador

CINAHPA | 2017 - Congresso Internacional de Ambientes Hipermídia para Aprendizagem.

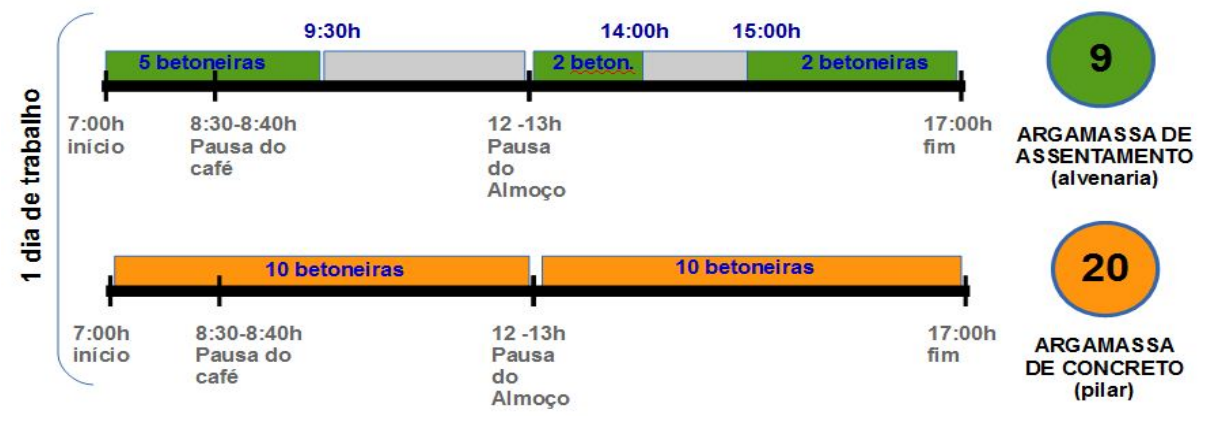

Figura 3 - Relação da produção diária de argamassas medidas em betoneiras Fonte: Os autores.

\begin{tabular}{|c|c|}
\hline Perspectiva & Verificações \\
\hline $\begin{array}{l}\text { Atividade pelo Servente de } \\
\text { Obra }\end{array}$ & $\begin{array}{l}\text { O dois operadores relatam como executam a produção de argamassas em obra, havendo modos de ação diferentes para o } \\
\text { mesmo objetivo. Nãohápadronizaçãonaseqüência do procedimento de produção. }\end{array}$ \\
\hline Temporal & $\begin{array}{l}\text { O ritmo de produção de argamassas varia conforme o tipo de argamassa solicitada, sendo a produção diária para a argamassa de } \\
\text { assentamento de } 09 \text { "betoneiras" (linguagem adotada em obra para medir a quantidade argamassa produzida) e para a } \\
\text { argamassa de concreto de } 20 \text { "betoneiras". Verfigura } 3 \text {. } \\
\text { - A produção mensal é determinada por } 3 \text { semanas produzindo argamassa de assentamento e } 01 \text { semana produzindo } \\
\text { argamassa de concreto, totalizando uma produção de } 235 \text { betoneiras. } \\
\text { - Em relação ao tempo de produção de } 1 \text { betoneira de argamassa, as observações e medições em campo indicam um } \\
\text { tempo médio de } 15 \text { minutos, desconsiderando o tempo necessário para reposição de insumos e auxílio ao pedreiro } \\
\text { de alvenaria. }\end{array}$ \\
\hline EsforçoFísico & $\begin{array}{l}\text { As cargas dos insumos manipulados foram medidas em quilogramas }(\mathrm{kg}) \text {, considerando os dois tipos de argamassas produzidas } \\
\text { e resultam em um peso entre } 52,2 \mathrm{~kg} \text { e } 61 \mathrm{~kg} \text { manuseada por cada operador na produção de } 1 \text { betoneira }\end{array}$ \\
\hline Comportamental e Cognitiva & $\begin{array}{l}\text { As observações no ambiente de trabalho de produção de argamassas em relação aos deslocamentos que os serventes de obra } \\
\text { realizam para completar os objetivos da tarefa prescrita elucidam um conflito de fluxos de circulação geral da obra com a } \\
\text { circulação no posto de trabalho em análise. Fato também verificado na resposta da entrevista com o servente de obras em que } \\
\text { ele argumenta o problema de trombar com outro trabalhador, os acidentes com ferramentas e a alteração do ritmo de produção. } \\
\text { - Outro fator observado é a inter-relação entre servente de obra e pedreiro. Os relatos dos serventes de obra } \\
\text { entrevistados emergem uma situação de estresse no momento da solicitação da argamassa, pois há uma } \\
\text { personalização do tipo de argamassa para cada pedreiro que a solicita em função de hábitos de trabalho anteriores } \\
\text { que definem a noção de massa "boa", "mole", "dura". O servente ao seguir a especificação da empresa, fixada no } \\
\text { quadro de argamassas, nem sempre é suficiente para determinados pedreiros, devendo aquele realizar pequenas } \\
\text { modificações empíricas no traço da argamassa, de modo a satisfazer a solicitação deste. Essa situação é de } \\
\text { conhecimento de todos na empresa (Figura 4). } \\
\text { Em relação às adaptações (estratégias) realizadas pelo operador para realizar atividade, os serventes de obra relatam que } \\
\text { realizam as seguintes ações para aperfeiçoar a atividade: } \\
\text { Peneirar areia antes de iniciar o ciclo da betoneira, deixando a padiola cheia; } \\
\text { - Abastecer com cimento o recipiente do depósito, de modo a sempre ter insumo disponível e minimizar o contato } \\
\text { freqüente com a poeira do cimento; } \\
\text { - Identificar qual pedreiro solicitou e o tipo e quantidade de argamassa, para saber qual será a adaptação necessária } \\
\text { para satisfazer o solicitante e evitar estresse; } \\
\text { Adoção de canal de comunicação direta entre pedreiro-servente através de um cano de PVC fixado na coluna perto } \\
\text { da betoneira e que alcança todos os andares ( Figura 4); } \\
\text { Lembrete do traço da argamassa ( quadro fixado na parede do posto de trabalho) para evitar escrever os lembretes } \\
\text { nas paredes da obra e minimizar os erros; }\end{array}$ \\
\hline Coletiva do Trabalho & 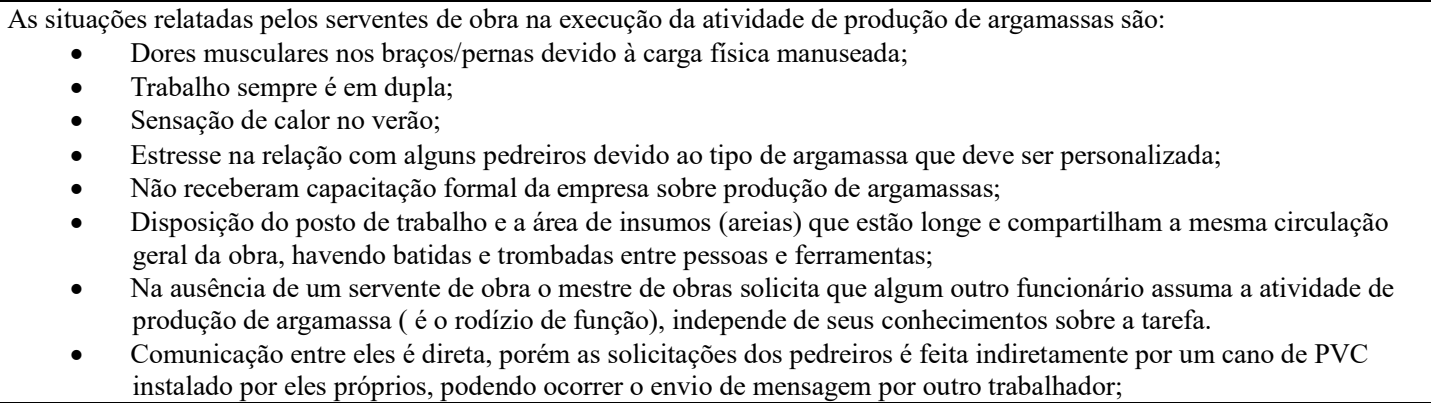 \\
\hline
\end{tabular}

Quadro 4 - Perspectivas verificadas na execução de atividade de produção de argamassa em obra. Fonte: Os autores

Realização:

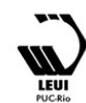

INSTITUTO FEDERAL

Santa Catarina Câmpus Palhoça Bilíngue 


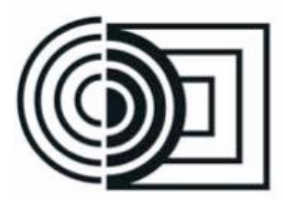
CINAHPA

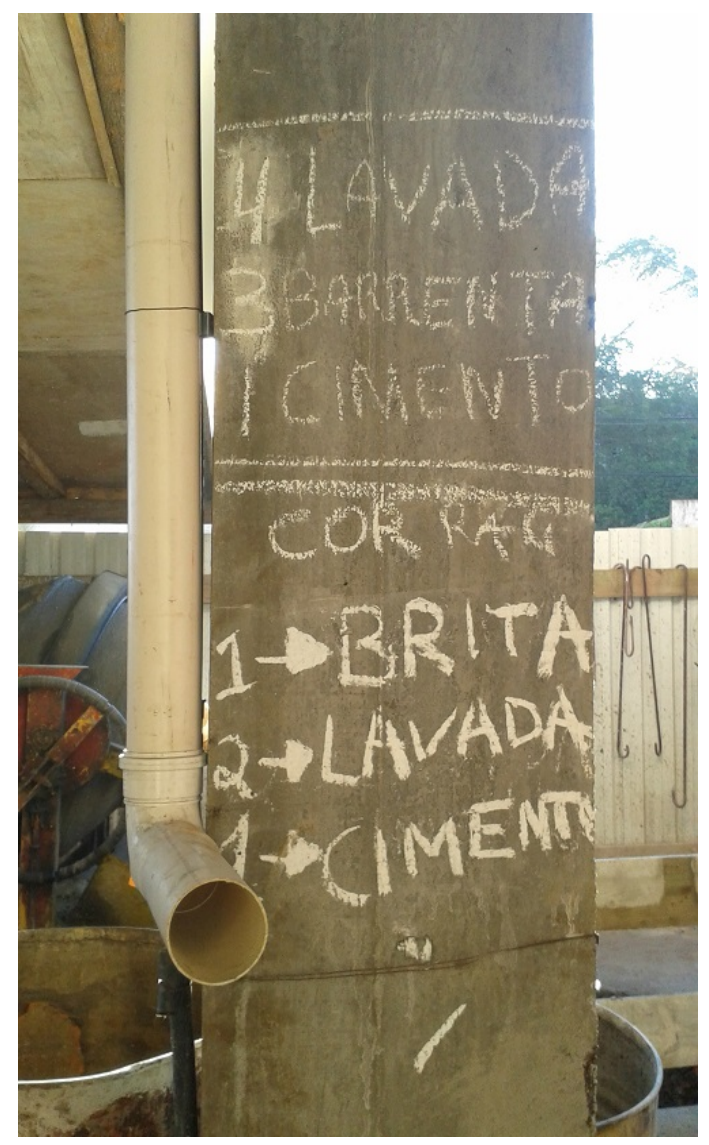

Figura 4- Imagem do cano em PVC adaptado para agilizar a comunicação entre servente e pedreiros, estratégia criada pelos serventes. Fonte: Os autores

\section{Resultados e Discussões}

A AET permite reconhecer em detalhes os fatores que interferem na demanda. Deste modo, a identificação desses fatores permite direcionar ações corretivas no intuito de responder à demanda inicial. Os fatores que interferem na demanda foram reconhecidos através da análise da atividade e revelados pelos operadores, sendo classificados em dois grupos de atuação: local (restrito ao posto de trabalho) e geral ( reflexo na estrutura da organização),conforme se apresenta a seguir no quadro 5. Por último, foram elencadas as situações de interferências normativas com base na NR-17

\subsection{Interferências Locais}

A síntese dos indicadores de ritmo de produção e $16^{\circ}$ Ergodesign - Congresso Internacional de Ergonomia e Usabilidade de Interfaces Humano Tecnológica: Produto, Informações Ambientes Construídos e Transporte

$16^{\circ}$ USIHC - Congresso Internacional de Ergonomia e Usabilidade de Interfaces Humano Computador

CINAHPA | 2017 - Congresso Internacional de Ambientes Hipermídia para Aprendizagem.

de carga física manuseada na atividade fornece base técnica indicativa de atenção à função de servente de obra. A partir de cálculos sobre o peso dos insumos carregados, chegou-se a previsão mensal de produção de argamassas que envolvem uma carga de quase 13 toneladas manuseadas por cada operador para poder atingirem a meta de produção de 235 betoneiras de argamassas, tendo um tempo de produção de no mínimo 15 minutos e no máximo 28 minutos para argamassas de assentamento, e no caso de argamassa de concreto o tempo máximo de 32 minutos.

\begin{tabular}{|c|c|}
\hline Interferênciasverificadas & Reflexo \\
\hline 1) exigência física (dor nos braços/pernas) & \multirow{6}{*}{ LOCAL } \\
\hline $\begin{array}{l}\text { 2) calor no período do verão (gera mal-estar, fraqueza } \\
\text { no operador) }\end{array}$ & \\
\hline 3) poeira do cimento (gera tosse, irritação na garganta) & \\
\hline $\begin{array}{l}\text { 4) organização do local da betoneira (disposição dos } \\
\text { insumos/ areia mais perto) }\end{array}$ & \\
\hline $\begin{array}{l}\text { 5) comunicação entre servente/pedreiro ( desgaste } \\
\text { físico de deslocamento) }\end{array}$ & \\
\hline $\begin{array}{l}\text { 6) não receberam treinamento formal sobre produção } \\
\text { de argamassa }\end{array}$ & \\
\hline $\begin{array}{l}\text { 7) colegas de trabalho "chatos" (personalizar o tipo de } \\
\text { argamassa) }\end{array}$ & \multirow[t]{2}{*}{ GERAL } \\
\hline $\begin{array}{l}\text { 8) rodízio na função ( substituição do servente de } \\
\text { obras, desconhece a atividade) }\end{array}$ & \\
\hline
\end{tabular}

Quadro 5 - Síntese das interferências verificadas na atividade e seu reflexo na organização. Fonte: Os autores

Quanto ao ritmo de trabalho, considera-se a atividade intensa pela quantidade de carga manuseada em um determinado espaço de tempo. A carga física operada em uma semana de produção de argamassa de concreto (6.100kg/operador) equivale, aproximadamente, à soma das três semanas de produção de argamassa de assentamento (6.937,5kg/operador). A aplicação do método NIOSH de cálculo de esforço físico para a operação de produção de argamassa resultou num índice de levantamento menor que 3 , cuja classificação é de atividade de risco moderado. No caso da operação de reposição de cimento resultou num índice de levantamento maior que 3 , cuja classificação é de atividade de risco intenso, conforme indicado na figura 5 e 6 .

O ambiente construído em que se encontra o posto
Realização:

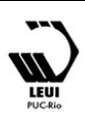




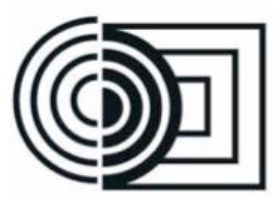

de trabalho é coberto e aberto nas laterais, possibilitando a ação das intempéries dentro do local (Ex:sujeito a ação de ventos, chuvas, frio, calor).

O layout adotado pela empresa no espaço da obra organizou o posto de trabalho de modo a aproximar a betoneira, o depósito de insumos e a caneca/concha da grua. Porém os relatos dos $16^{\circ}$ Ergodesign - Congresso Internacional de Ergonomia e Usabilidade de Interfaces Humano Tecnológica: Produto, Informações Ambientes Construídos e Transporte

$16^{\circ}$ USIHC - Congresso Internacional de Ergonomia e Usabilidade de Interfaces Humano Computador

CINAHPA | 2017 - Congresso Internacional de Ambientes Hipermídia para Aprendizagem.

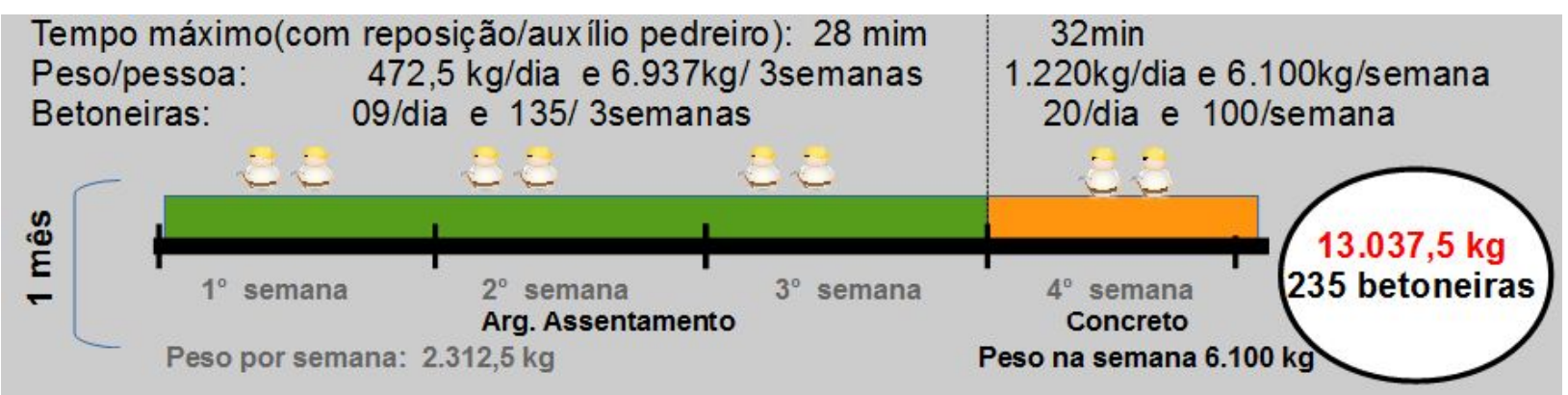

Figura 5 - Síntese de indicadores verificados na execução da atividade de produção de argamassas no período de 1 mês. Fonte: Os autores
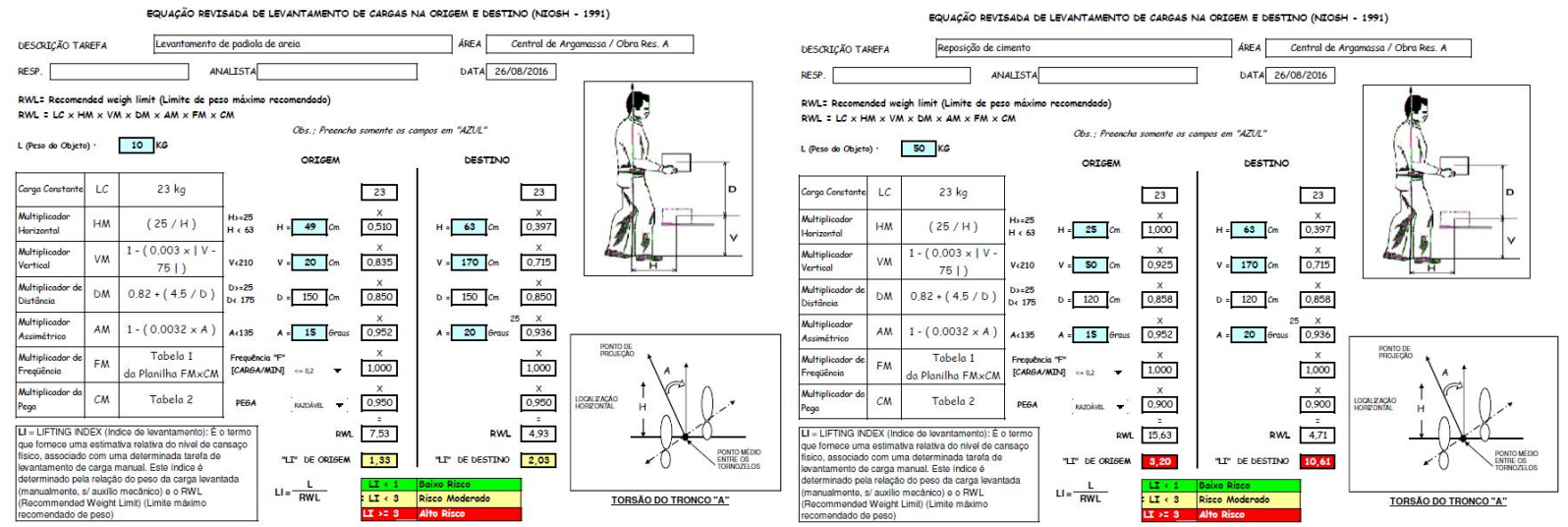

Figura 6 - Resultado do cálculo de esforço físico pelo método NIOSH considerando a atividade de levantamento de padiolas (Esquerda) $\mathrm{LI}=2,03$ e a de reposição de cimento (Direita) $\mathrm{LI}=10,61$.

Quanto a disposição dos insumos (cimento, brita, areia, aditivo, água), apenas o depósito de cimento é fechado e requer que todo dia seja recarregado o recipiente deste insumo, cuja formato em caixa possui uma tampa que só é fechada ao final da jornada. No momento de despejar o saco de cimento $(50 \mathrm{~kg})$, geram-se partículas sólida em suspensão (poeira do pó de cimento) que são inaladas pelo operador e demais pessoas presentes no posto de trabalho, e a tampa do recipiente é mantida aberta facilitando a proliferação da poeira. $\mathrm{O}$ uso de equipamento de proteção individual atenua o contato da poeira com a boca e nariz, porém o resto do corpo fica em contato com esse agente químico. $\mathrm{O}$ fechamento da tampa existente na caixa poderá minimizar o fluxo da poeira $\mathrm{e}$ restringir seu campo de atuação as imediações da caixa de cimento. Ver figura 7.
Realização:

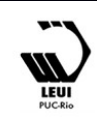



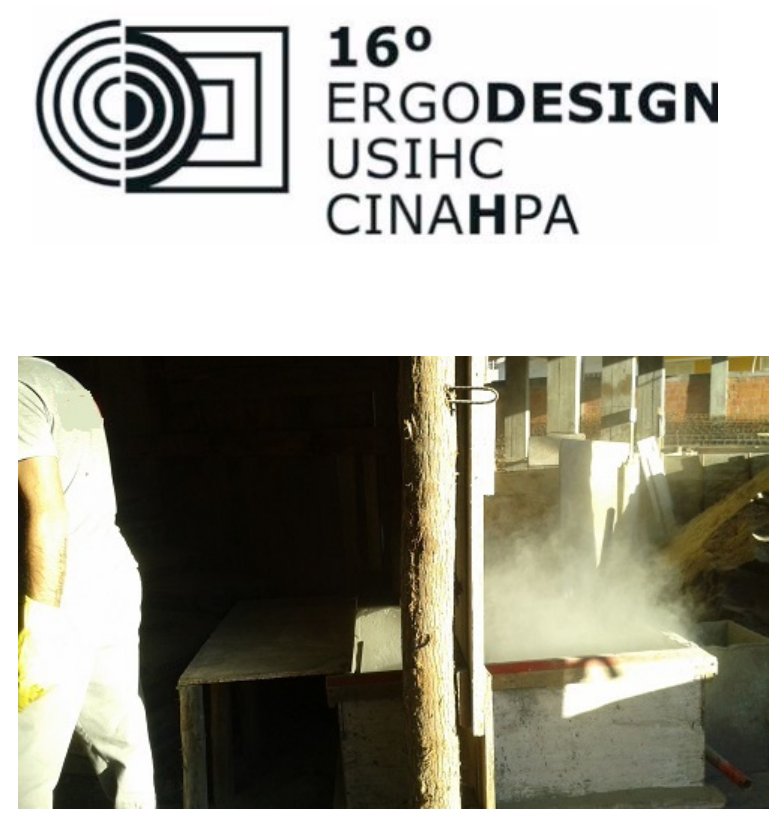

Figura 7 - Caixa de cimento com tampa aberta no momento da recarga e a poeira gerada. Fonte: Os autores.

A comunicação entre o servente e pedreiro é constante na jornada de trabalho para solicitar a produção de argamassa, que varia em tipo e em quantidade. Quem determina o tipo e quantidade de argamassa é o pedreiro e o mestre de obras que a solicita. $\mathrm{O}$ edifício em construção possui 10 pavimentos e a circulação vertical é feita a pé, por meio de escada em concreto da própria construção. Os serventes relam que costumavam subir várias vezes as escadas até o encontro do pedreiro para saber se havia necessidade de nova produção de argamassa ou se necessitava de auxílio, fato que lhes rendia cansaço físico extra devido ao deslocamento vertical. Uma estratégia adotada pelo servente para otimizar a comunicação e minimizar o cansaço foi a implantação de um duto de comunicação fixado na parede do posto de trabalho e que alcança todos os andares da construção. Assim o pedreiro se desloca até o duto, se comunica com o servente e em seguida é entregue a argamassa no local solicitado. Ver figura 4.

Esse duto de comunicação também auxilia na identificação de quem solicita a argamassa, pois segundo relatos dos serventes há necessidade de adaptação do traço da argamassa para determinados pedreiros (Ex:.argamassa mais mole, argamassa mais dura). A identificação do pedreiro que solicita material permite ao servente fazer os ajustes empíricos na argamassa, variando a dose de água, e reduz os conflitos sobre padrão de argamassa boa, uma vez que cada pedreiro carrega uma definição de argamassa "boa ou ruim" devido às suas experiências anteriores na função. $16^{\circ}$ Ergodesign - Congresso Internacional de Ergonomia e Usabilidade de Interfaces Humano Tecnológica: Produto, Informações Ambientes Construídos e Transporte

$16^{\circ}$ USIHC - Congresso Internacional de Ergonomia e Usabilidade de Interfaces Humano Computador

CINAHPA | 2017 - Congresso Internacional de Ambientes Hipermídia para Aprendizagem.
Em entrevistas, os serventes relatam essa relação com os pedreiros de tensa, pois nem sempre conseguem acertar o "ponto da argamassa ideal" para cada pedreiro. A empresa conhece essa situação e não realizou capacitação com eles sobre produção de argamassa. Eles relatam que sabem produzir argamassa seguindo as informações do quadro fixado na parede e porque alguma vez observam outro servente produzir argamassa e repete suas ações.

\subsection{Interferências Gerais}

A relação entre servente e pedreiro pode ser tensa no momento da produção de argamassa devido à falta de padronização de uma argamassa "boa ou ruim" dentro da empresa. Esse desconforto relatado pelos serventes extrapola o espaço do posto de trabalho e reflete nas relações interpessoais dentro e fora do ambiente de trabalho. Há a rotulação entre os trabalhadores da obra de "pedreiro chato", "servente ruim". Esses constrangimentos no ambiente interferem na demanda.

Outro fato relatado pelos serventes e pelo técnico em segurança do trabalho da obra é a adoção de rodízio de função na produção de argamassas que é motivada quando há ausência de um servente de obra. O trabalho de produção de argamassa é em dupla e o mestre de obras faz a solicitação a qualquer outro trabalhador da obra para assumir o posto de trabalho da betoneira quando necessário. Nesta situação, o novo operador não tem conhecimento da atividade real de produção de argamassa, apenas uma noção da tarefa prescrita. Essa prática da empresa pode resultar em questionamentos jurídicos e trabalhistas por desvio de função, em acidentes de trabalho e em alteração no fluxo de produção de argamassas, haja vista a condição do trabalho imposta ao operador substituto.

\subsection{Interferência Normativa}

Verifica-se que a norma NR-17 é atendida parcialmente neste posto de trabalho pela empresa e há itens em desacordo com o estabelecido pela legislação sobre ergonomia, tais como:
Realização:
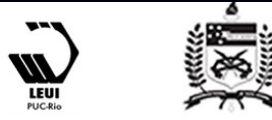


\section{$16^{\circ}$ \\ ERGODESIGN USIHC CINAHPA}

- Esforço físico intenso na semana de produção de argamassa de concreto não é adequado com a diretriz de manter a condição de saúde e de segurança do trabalhador (item 17.2 da NR-17);

- Não há assentos para descanso no posto de trabalho com atividade executada em pé (item 17.3 da NR-17);

- As condições ambientais de trabalho no período do verão são desconfortáveis (calor), gerando fraqueza, sudorese e cansaço conforme relato dos serventes de obra (item 17.5 da NR-17);

- A organização do trabalho de produção de argamassa na obra apresenta-se pouco organizado, desconsiderando questões de atividade real, estratégias aplicadas, limitações da atividade e nível de conhecimento dos operadores sobre a tarefa prescrita (item 17.6, incisos "a,b,c", da NR-17);

- Não há pausas oficiais estabelecidas na tarefa prescrita (intercaladas no processo de produção da argamassa), apenas há a pausa habitual da empresa para o café da manhã (10 minutos) (item 17.6, inciso "d", da NR-17).

\subsection{Diagnósticos e Soluções Propostas}

As proposições abaixo objetivam corrigir as interferências verificadas na atividade de modo a dar garantia a demanda. No quadro 6 , apresentamse a relação das soluções propostas com o cronograma de ações e a definição do setor responsável pela execução dentro do prazo estimado. As ações corretivas no estudo realizado possuem uma ordem de execução, de acordo com as situações mais urgentes de intervenção:

Em primeiro lugar de ação está a formulação de uma capacitação sobre produção de argamassas na construção civil. Esta recomendação surge do relato dos serventes de obra e o reflexo dessa ação atua em outro setor da empresa, como o da produção de alvenaria (pedreiros). A estrutura dessa capacitação pode ser realizada em parceria com instituições de ensino da cidade. $16^{\circ}$ Ergodesign - Congresso Internacional de Ergonomia e Usabilidade de Interfaces Humano Tecnológica: Produto, Informações Ambientes Construídos e Transporte

$16^{\circ}$ USIHC - Congresso Internacional de Ergonomia e Usabilidade de Interfaces Humano Computador

CINAHPA | 2017 - Congresso Internacional de Ambientes Hipermídia para Aprendizagem.
Em segundo lugar está a revisão do layout do posto de trabalho de modo a corrigir os fluxos de circulação e de localização de insumos. Ver fig.8.

A terceira ação objetiva aprofundar o estudo sobre a carga física de trabalho do servente na produção de argamassas em que aponta a necessidade de análise sobre adoção de concreto usinado ou de estudo específico de alimentação e transporte de insumos para o posto de trabalho.

Em quarto lugar está a revisão formato de rodízio de funções para substituir um servente em sua ausência. Há considerações de aspeto jurídico e trabalhista, ergonômico e de ordem produtiva a serem considerados.
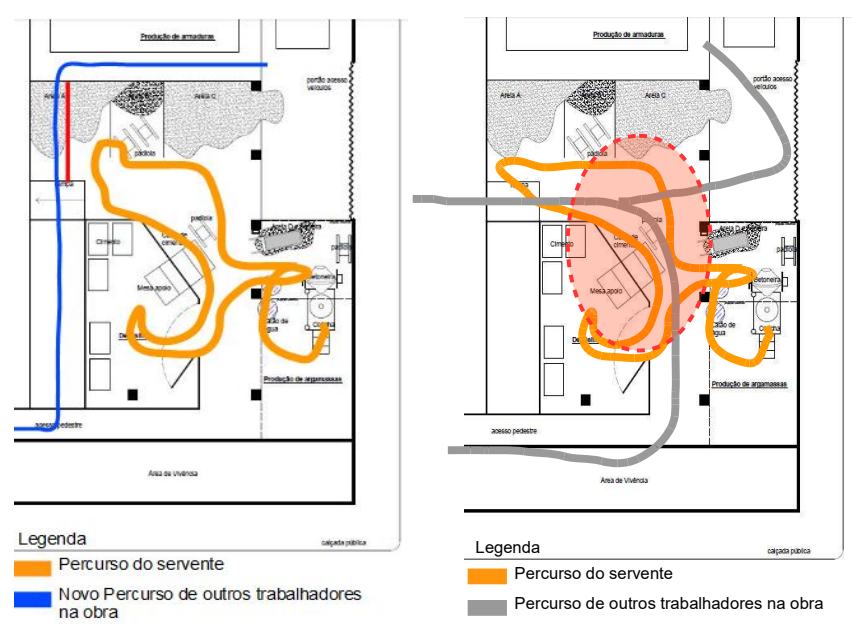

Figura 8 - Sugestão de novo layout do posto de trabalho, destaque a nova rota de circulação geral de pessoas diferenciada da circulação do no posto de trabalho (direita). Layout original de circulação conflituosa no posto de trabalho (esquerda).

\section{Considerações Finais}

A atividade executada pelo servente de obra na produção de argamassas da empresa analisada apresenta interferências positivas e negativas, que agem sobre a otimização do processo de produção de argamassas na obra analisada em Criciúma/SC.

Algumas estratégias desenvolvidas pelos próprios operadores impactam positivamente sobre a atividade, como a criação do canal de comunicação em cano de PVC - material comum e presente na obra, e que garantiu a eficiência de comunicação
Realização:

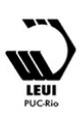




\section{$16^{\circ}$ \\ ERGODESIGN USIHC CINAHPA}

$16^{\circ}$ Ergodesign - Congresso Internacional de Ergonomia e Usabilidade de Interfaces Humano Tecnológica: Produto, Informações Ambientes Construídos e Transporte

$16^{\circ}$ USIHC - Congresso Internacional de Ergonomia e Usabilidade de Interfaces Humano Computador

CINAHPA | 2017 - Congresso Internacional de Ambientes Hipermídia para Aprendizagem. entre serventes e pedreiros. Outro exemplo, a anotação do traço da argamassa em paredes pelos operadores e que o técnico em Segurança do Trabalho observou e ajustou as informações e oficializou-a na forma de quadro fixado em parede.

Os fatores negativos verificados, como o layout e a falta de capacitação, precisam ser tratados logo para que possam impactar positivamente no posto de trabalho e na organização da empresa.

O modo de reposição e transporte de materiais impacta negativamente sobre o servente de obra, de tal modo que a carga física manuseada é considerável e pode requerer ajustes do posto de trabalho em níveis de alteração do processo ou de adoção de outra tecnologia de produção de argamassa (ex.: concreto usinado).

Ao se planejar uma tarefa deve-se considerar que ela será executada por operadores com estruturas físicas diferentes, logo se deve considerar no momento da elaboração da tarefa prescrita fatores como deslocamentos, alcance de manobras, cargas físicas e mentais exigidas.

O manuseio de cargas no ambiente de trabalho requer estudo específico, envolvendo as posturas e as cargas manuseadas, para se reconhecer a dimensão da atividade real e seu nível de exigência física do operador. Sempre que possível, um meio auxiliar deve ser utilizada para substituir o transporte manual de cargas.

Posto isso, após a aplicação das propostas de solução, a empresa deve realizar uma análise da organização do trabalho de produção de argamassas em obra, estabelecendo uma nova estrutura de trabalho que delimite objetivos reais para a meta, considerando: pausas intercaladas no processo de produção e disponibilize assentos adequados para descanso no posto de trabalho; meios auxiliar de transporte de materiais ou alteração de método de fornecimento de concreto e a padronização sobre processo de produção das argamassas utilizadas em obra. Desde modo, a demanda será atendida com maior constância pela empresa.

\section{BIBLIOGRAFIA}

ASSOCIAÇÃO BRASILEIRA DE NORMAS TÉCNICAS. NBR- 12284: Áreas de Vivência em Canteiros de Obras. Rio de Janeiro, 1991.

BRASIL.Portaria $\mathrm{n}^{\circ}$ 3.214 do Ministério do Trabalho e Emprego de 08 de junho de 1978. Institui as Normas Regulamentadoras no Brasil. $<$ http://trabalho.gov.br/seguranca-e-saude-notrabalho/normatizacao/normasregulamentadoras/norma-regulamentadora-n-17ergonomia> Acesso em 05/09/2016.

IBGE: Indústria de transformação garantiu PIB maior. [Internet]. São Paulo: Grupo Estado [data da publicação 30/08/2013; citado 30/10/2014]. Disponível em: http://economia.estadao. com.br/noticias/geral,ibge-industria-detransformacao-garantiu-pib-maior,163398e .

IEA - Associação Internacional de Ergonomia. Disponível em: <http://www.abergo.org.br /internas.php?pg=o_que_e_ergonomia $>$. Acesso em 05/09/2016.

FERREIRA, Emerson de Andrade Marques. Metodologia para elaboração do projeto de canteiro de obras de edifícios. E.A.M. FERREIRA, L.S. FRANCO. São Paulo, 1998. Boletim Técnico da Escola Politécnica da Universidade de São Paulo. (Departamento de Engenharia de Construção, Civil BT/PCC/210)

GONTIJO, Leila A..Material de aula da disciplina de Análise Ergonômica do Trabalho do Programa de Pós-Graduação de Engenharia de Produção da Universidade Federal de Santa Catarina. Florianópolis, UFSC, 2016.

SAURIN, Tarcisio Abreu, FORMOSO, Carlos Torres. Planejamento de canteiros de obra e gestão de processos. Porto Alegre : ANTAC, 2006. (Recomendações Técnicas HABITARE,v. 3).

WISNER, Alan. Um Objetivo Maior A

Inteligência No Trabalho. In A Inteligência no Trabalho, Textos selecionados de ergonomia. São Paulo, UNESP, FUNDACENTRO, 1994. 